\title{
On the Monophyly of the Agamid Genus Gonocephalus Kaup, 1825 (Reptilia: Squamata): A Chromosomal Perspective
}

\author{
Cheong-Hoong DIONG ${ }^{1}$, MAY-Hon LOW ${ }^{1}$, Ene-Choo TAN ${ }^{2}$, HoI-SeN \\ YONG $^{3}$, Tsutomu HIKIDA ${ }^{4}$, AND HIDETOSHI OTA ${ }^{5 *}$
}

${ }^{1}$ Division of Biology, School of Science, Nanyang Technological University, 469 Bukit Timah Road, SINGAPORE 258756

${ }^{2}$ Institute of Cell and Molecular Biology, National University of Singapore, SINGAPORE 117609

${ }^{3}$ Institute of Biological Sciences, University of Malaya, 50603, Kuala Lumpur, $M A L A Y S I A$

${ }^{4}$ Department of Zoology, Graduate School of Science, Kyoto University, Kitashirakawa, Sakyo-ku, Kyoto 606-8502, JAPAN

${ }_{5}^{5}$ Tropical Biosphere Research Center, University of the Ryukyus, Nishihara, Okinawa 903-0213, JAPAN

\begin{abstract}
We karyotyped five species of the agamid genus Gonocephalus, $G$. chamaeleontinus, G. liogaster, G. bellii, G. grandis (from Peninsular Malaysia), and $G$. robinsonii. Of these, karyotypes of the first four species had several chromosomal characteristics exclusively shared with the previously reported karyotypes of G. miotympanum and G. grandis (from Borneo), such as the diploid chromosome number (42) and the presence of 22 biarmed macrochromosomes. This seems to support the monophyly of those four species and $G$. miotympanum, probably along with some other species of the genus not yet karyotyped. This hypothesis is premised on our finding of distinct chromosomal characteristics that are indicative of highly derived states in the agamid karyotypes. The karyotype of $G$. robinsonii, while remarkably different from other congeneric karyotypes in exhibiting much smaller diploid (32) and biarmed macrochromosome numbers (12), share these and other chromosomal characteristics with several Australian species. It seems unlikely for the karyotype of $G$. robinsonii to directly emerge from other congeneric karyotypes or vice versa. We conclude that the inclusion of this species in Gonocephalus would render the genus paraphyletic.
\end{abstract}

Key words: Reptilia; Agamidae; Gonocephalus belli; G. chamaeleontinus; G. liogaster; G. grandis; G. robinsonii; Karyotype; Monophyly

* Corresponding author. Tel: + 81-98-8958937; Fax: +81-98-895-8966.

E-mail address: ota@sci.u-ryukyu.ac.jp (H. Ota)

\section{INTRODUCTION}

The agamid genus Gonocephalus Kaup, 1825 , is a group of moderate-sized to large lizards. Darlington (1957) argued that the 
genus is zoogeographically exceptional, because it was then considered to occur on both sides of Wallace's Line, a zoogeographic border between the Oriental and Australian faunas. Based on the microchromosome numbers, Witten (1983) also postulated that the Australian species assigned to Gonocephalus at that date represent recent dispersals from Southeast Asia across Wallace's Line.

In his unpublished Ph.D. dissertation, Moody (1980), on the basis of phylogenetic analysis of morphological characters, asserted that the Gonocephalus species east of Wallace's line were derived from radiations of the Australian stock, and that they are phylogenetically distant from the Southeast Asian species. He further argued that the genus Hypsilurus Peters, 1867, once synonymized to Gonocephalus by Boulenger (1885), should be resurrected to accommodate species from the Australian Region. Results of more recent immunogenetic (Baverstock and Donnelan, 1990; King, 1990), karyological (Ota et al., 1992), electron-microscopic (Ananjeva and Matveyeva-Dujsebayeva, 1996), and molecular studies (Honda et al., 2000) favored Moody's (1980) view. All recent authors, with the exception of a few who have obviously overlooked these works (e.g., Urban, 1999), restrict the application of the generic name, Gonocephalus, to the Southeast Asian species (Welch et al., 1990; Manthey and Grossmann, 1997).

In all those works addressing the phylogeny of Gonocephalus (sensu lato), however, the species assemblage on the western side of Wallace's Line (i.e., Gonocephalus [sensu stricto]), though constituting no less than 16 species (Welch et al., 1990; Manthey and Grossmann, 1997), was represented by very few species. For example, Moody (1980) examined osteological specimens for only five species. Furthermore, Baverstock and Donnellan (1990), Ota et al. (1992), Ananjeva and Matveyeva-Dujsebayeva (1996), and Honda et al. (2000) examined only one, two, four, and one species, respectively. Considering that a thorough definition of Gonocephalus (sensu stricto) depends only on a few external characters (Moody, 1980; Manthey and Grossmann, 1997), the monophyly of the genus is obviously yet to be examined.

Ota et al. (1992) reported that G. grandis and G. miotympanum, both from Borneo, share characteristic chromosomal arrangements that are obviously in highly derived states. This suggests that the karyological approach may be an effective way to examine the monophyly of the genus. Therefore, in this study, we karyotyped four additional species of Gonocephalus including its type species, G. chamaeleontinus, as well as G. grandis from the Peninsular Malaysia.

\section{Materials And Methods}

Except for two male Gonocephalus robinsonii, all lizards, collected from Peninsular Malaysia and Pulau Tioman (Table 1), were transported to the laboratory where they were injected intraperitoneally with $0.1 \mathrm{ml}$ of colchicine solution $(2 \mathrm{mg} / \mathrm{ml})$ per gram of body weight. Sixteen to $18 \mathrm{~h}$ after injection, they were anesthesized with diethyl ether and were dissected to remove femur bones. Bone marrow were flushed out from the bones with Hanks balanced buffer solution. For each sample, the cell suspension was left to stand for $10 \mathrm{~min}$ before it was centrifuged at $2000 \mathrm{rpm}$ for $5 \mathrm{~min}$. Bone marrow cells were then treated with hypotonic $\mathrm{KCl}$ solution $(0.06$ mole $/ 1)$ at room temperature (26$28^{\circ} \mathrm{C}$ ) for $1 \mathrm{~h}$, followed by fixation in a $1: 3$ glacial acetic acid : absolute methyl alcohol mixture. Mitotic chromosome slides were prepared by the splash technique, air-dried, and were stained in 6\% Gurr Giemsa (BDH) solution. Mitotic cell slides for the remaining two male G. robinsonii were prepared in the field following Ota (1989a), and were stained in $2 \%$ Giemsa solution. 
TABLE 1. Localities, sizes, and sexual compositions of samples of five Gonocephalus species examined in this study.

\begin{tabular}{lcccl}
\hline Species & \multicolumn{3}{c}{$\mathrm{N}$} & \\
\cline { 2 - 4 } G. bellii & 2 & 3 & 5 & $\begin{array}{l}\text { Gombak Forest Reserve, Peninsular Malaysia } \\
\left(03^{\circ} 09^{\prime} \mathrm{N}, 101^{\circ} 39^{\prime} \mathrm{E}\right)\end{array}$ \\
G. chamaeleontinus & 3 & 0 & 3 & $\begin{array}{l}(\mathrm{Pulau} \text { Tioman, near Peninsular Malaysia } \\
\left(02^{\circ} 49^{\prime} \mathrm{N}, 104^{\circ} 09^{\prime} \mathrm{E}\right)\end{array}$ \\
G. liogaster & 0 & 3 & 3 & $\begin{array}{l}\text { Gombak Forest Reserve, Peninsular Malaysia } \\
\left(03^{\circ} 09^{\prime} \mathrm{N}, 101^{\circ} 39^{\prime} \mathrm{E}\right)\end{array}$ \\
G. grandis & 3 & 3 & 6 & $\begin{array}{l}\text { Pulau Tioman, near Peninsular Malaysia } \\
\left(02^{\circ} 49^{\prime} \mathrm{N}, 104^{\circ} 09^{\prime} \mathrm{E}\right)\end{array}$ \\
G. robinsonii & 3 & 0 & 3 & $\begin{array}{l}\text { Cameron Highlands Peninsular Malaysia } \\
\left(04^{\circ} 28^{\prime} \mathrm{N}, 101^{\circ} 20^{\prime} \mathrm{E}\right)\end{array}$ \\
\hline
\end{tabular}

Karyotypes were determined for each individual lizard on the basis of 8-20 wellspread metaphase cells. Selected cell spreads were photographed with a Nikon Optiphot 2 Photomicrography camera using Kodak TMAX ASA 100 film. Individual chromosome pairs were arranged in decreasing size. For the calculation of arm ratio for each chromosome pair, the lengths of chromosome arms were measured with a CALCOM digitizer. Terminology for chromosomal descriptions follows Green and Sessions (1991), and the karyotype formula follows Peccinini-Seale (1981). Voucher specimens were deposited in the Zoological Reference Collection, Depart- ment of Biological Sciences, National University of Singapore (ZRC) and Herpetological Collection, Department of Zoology, Kyoto University (KUZ).

\section{RESULTS}

In all Gonocephalus species examined, karyotypes consisted of chromosomes forming large and smaller size-groups that are referred to here as macrochromosomes and microchromosomes, respectively (Table 2). Of these, macrochromosomes were all bi-armed, whereas detailed morphology remained undetermined for most microchromosomes. No sex chromosome hetero-

TABLE 2. Karyotypes of species of the genus Gonocephalus. $\mathrm{M}=$ macrochromomes; $\mathrm{m}=$ microchromosomes.

\begin{tabular}{lcccl}
\hline Species & 2n & $\begin{array}{c}\text { Arm nos. } \\
\text { in macro- } \\
\text { chromosomes }\end{array}$ & $\begin{array}{c}\text { Chromosomal } \\
\text { formula }\end{array}$ & Source \\
\hline G. bellii & 42 & 44 & $22 \mathrm{M}+20 \mathrm{~m}$ & this study \\
G. chamaeleontinus & 42 & 44 & $22 \mathrm{M}+20 \mathrm{~m}$ & this study \\
G. liogaster & 42 & 44 & $22 \mathrm{M}+20 \mathrm{~m}$ & this study \\
G. robinsonii & 32 & 24 & $12 \mathrm{M}+20 \mathrm{~m}$ & this study \\
G. grandis (Pulau Tioman) & 42 & 44 & $22 \mathrm{M}+20 \mathrm{~m}$ & this study \\
G. grandis (Borneo) & 42 & 44 & $22 \mathrm{M}+20 \mathrm{~m}$ & Ota et al. (1992) \\
G. miotympanum & 42 & 44 & $22 \mathrm{M}+20 \mathrm{~m}$ & Ota et al. (1992) \\
\hline
\end{tabular}


morphisms or secondary constrictions were evident in any karyotypes.

Karyotypes of $G$. chamaeleontinus, $G$. liogaster, G. bellii, and G. grandis consisted of $2 \mathrm{n}=42$ chromosomes, including 22 macrochromosomes (pairs 1-11) and 20 microchromosomes (pairs 12-21). The macrochromosomes of $G$. chamaeleontinus and $G$. liogaster were all metacentric (Fig. 1). From these, macrochromosomes of $G$. bellii and $G$. grandis differed in including submetacentric elements in pairs 1, 4 and 10, and pairs 2, 5, 7 and 9, respectively (Fig. $2)$. Thus, the arm numbers in macrochromosomes were 44 in all of the four karyotypes. With respect to the microchromosomes, the largest pair (i.e., pair 12) of the G. bellii karyotype was distinctly enlarged compared to the chromosome pair immediately following, thus obscuring the size-gap difference between the macro- and microchromosomes. In contrast, chromosome pair 12 was almost as small as pair 13 in karyptypes of $G$. chamaeleontinus, $G$. liogaster, and $G$. grandis, resulting in a more prominent size-gap difference between the two groups of chromosomes.

The karyotype of $G$. robinsonii differs remarkably from those of the other four Gonocephalus species in having substantially fewer $(2 n=32)$ chromosomes. Of the diploid chromosomes, 12 (pairs 1-6) were metacentric macrochromosomes, whereas the remaining 20 (pairs 7-16) were microchromosomes (Fig. 3). Therefore, the arm number in macrochromosomes of this karyotype equaled 24 .

\section{DisCUSSION}

Karyotypes of $G$. chamaeleontinus, $G$. bellii, G. liogaster, and G. grandis from Peninsular Malaysia and Pulau Tioman share similar chromosomal features with those of G. miotympanum and G. grandis from Borneo (Ota et al., 1992). In contrast, the karyotype of $G$. robinsonii differs strikingly from other congeneric karyo- types.

In the family Agamidae, two karyomorphs are typical: (1) $2 n=34$ or 36 chromosomes, including six pairs of metacentric or submetacentric macrochromosomes and 11 or 12 pairs of microchromosomes; and (2) $2 n=46$ or 48 chromosomes, all telocentric chromosomes without a distinct sizebreak (Bickham, 1984; King, 1981; Moody and Hutterer, 1978; Olmo, 1986; Ota and Hikida, 1989; Solleder and Schmid, 1988; Witten, 1983). One of these karyomorphs is considered to be derived from the other through a series of Robertsonian rearrangements of macrochromosomes, sometimes accompanied with addition or deletion of one microchromosome pair (Bickham, 1984; King, 1981). Judging from the fact that both of the two karyomorphs sometimes occur in a single genus or closely related genera (Gorman and Shochat, 1972; Ota, 1988, 1989b) and that there are so few karyotypes representing intermediate states between the two extremes, such chromosomal rearrangements may proceed rapidly when they are once triggered (King, 1981).

It is obvious that the karyotypes of $G$. chamaeleontinus, G. bellii, G. liogaster, $G$. grandis, and G. miotympanum could not be derived from either of the two typical agamid karyomorphs merely through Robertosonian rearrangements of macrochromosomes and slight numerical changes of microchromosomes, because these karyotypes include a much larger number of biarmed macrochromosomes (22) than those of any other agamid karyotypes hitherto reported, and at the same time, exhibit a greater diploid number (42) than the agamid karyomorph (1). Moreover, their fundamental number $(\mathrm{NF},>64)$ is considerably greater than those with karyomorph (2) $(\mathrm{NF}=46$ or 48$)$. We thus consider karyotypes of the five Gonocephalus species to represent a highly derived state, and that the chromosomal features exclusively shared among these species support 

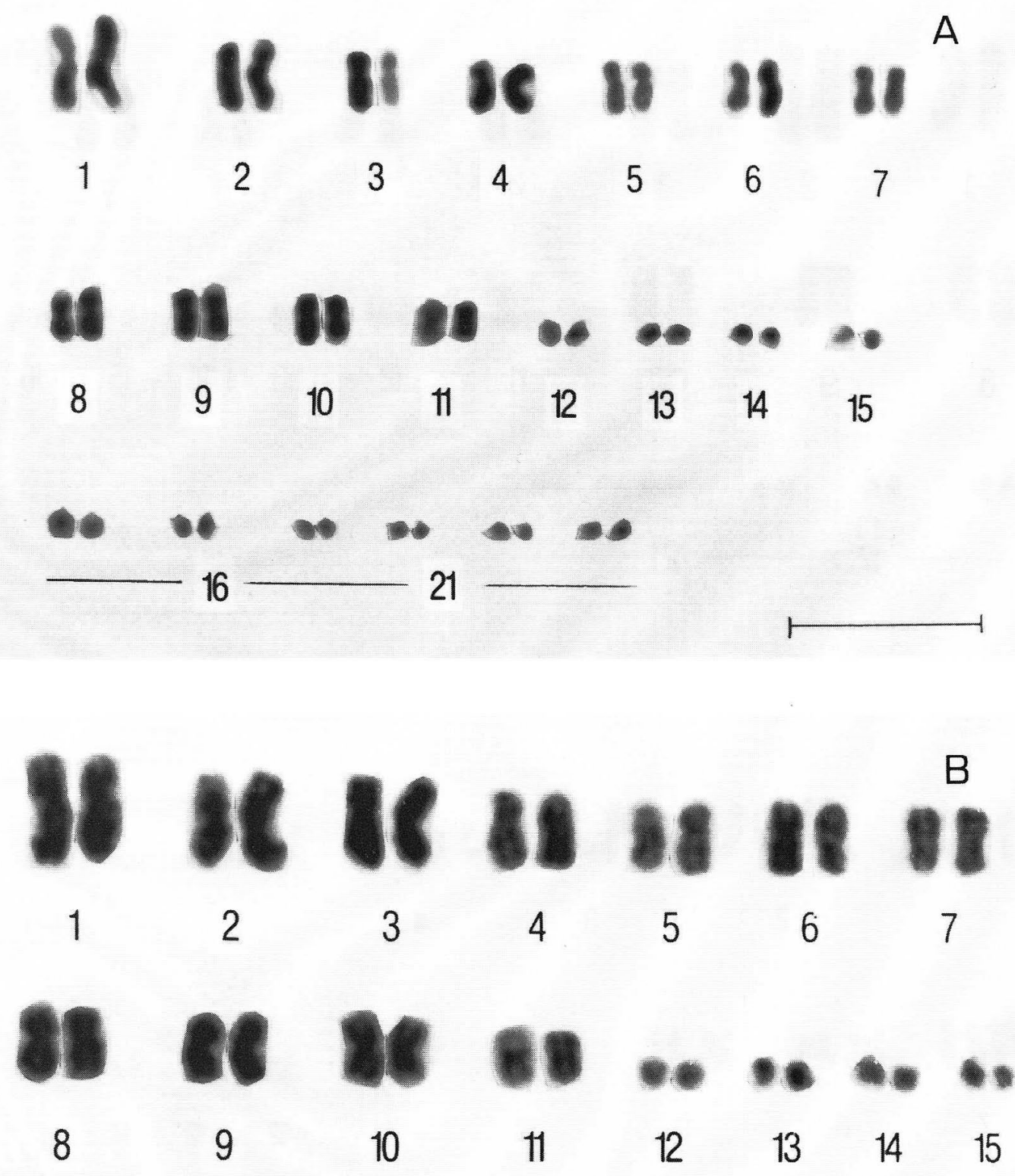

\section{0 e. 00 se sa}
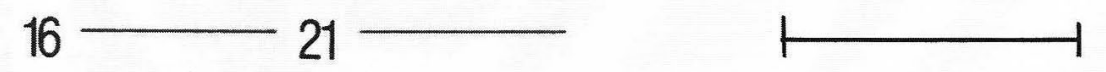

FIG. 1. Karyotypes of (A) Gonocephalus chamaeleontinus, and (B) G. liogaster. Bars equal $5 \mu \mathrm{m}$. 

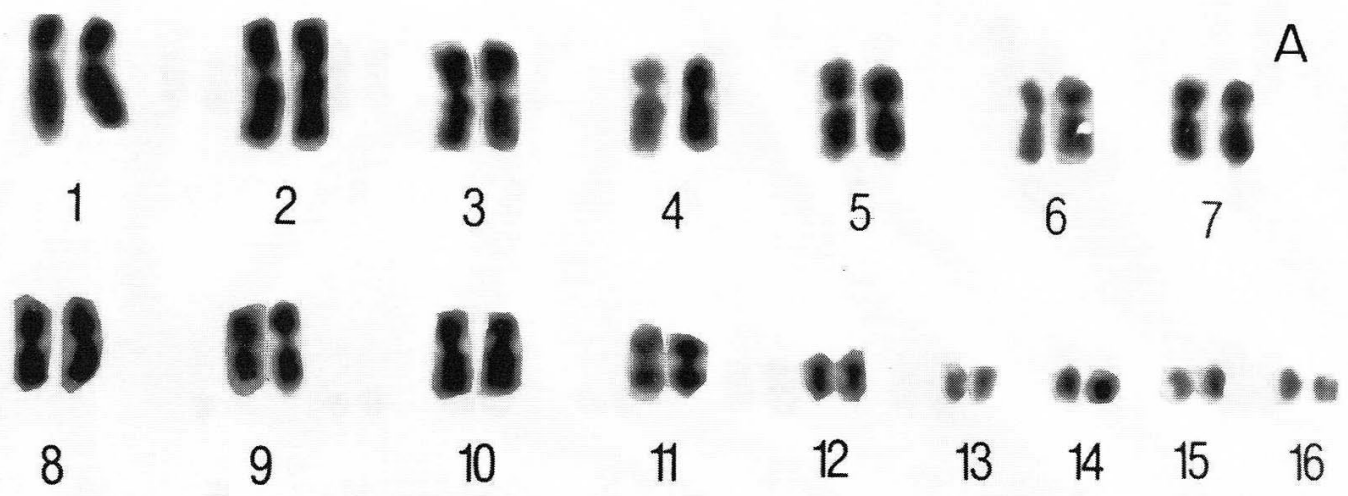

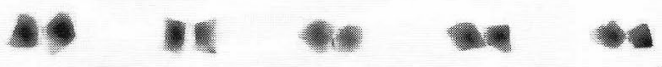

$-17-21-$
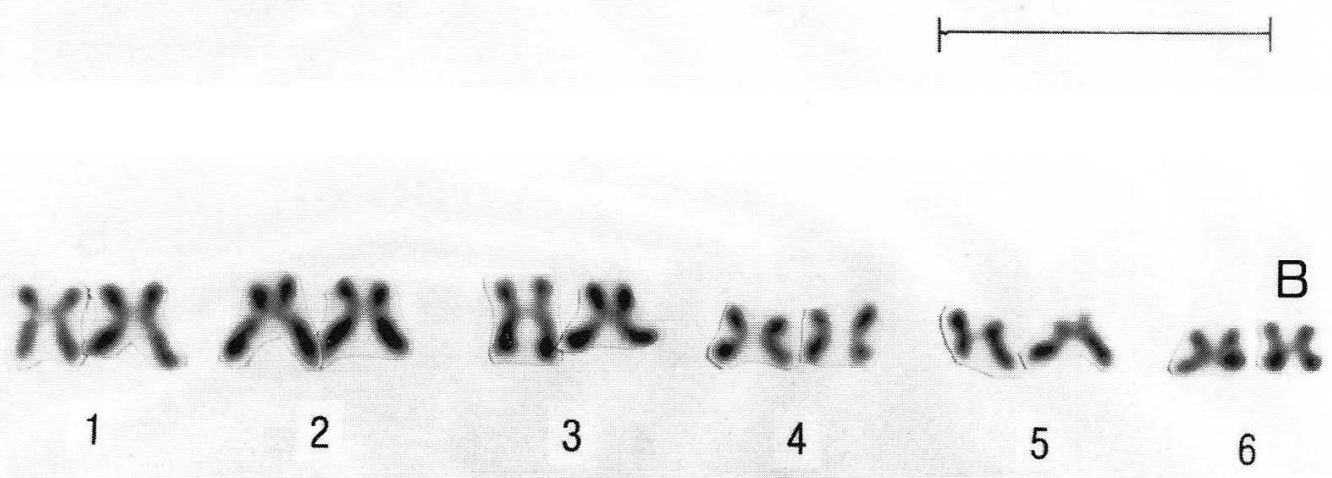

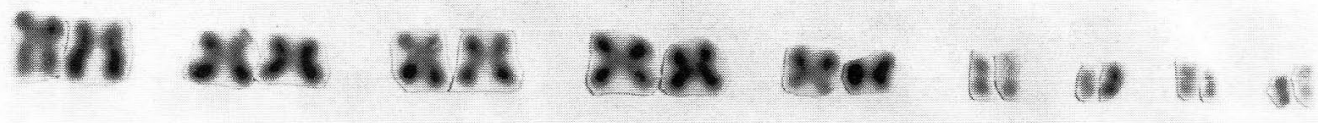

$\begin{array}{lllllllll}7 & 8 & 9 & 10 & 11 & 12 & 13 & 14 & 15\end{array}$

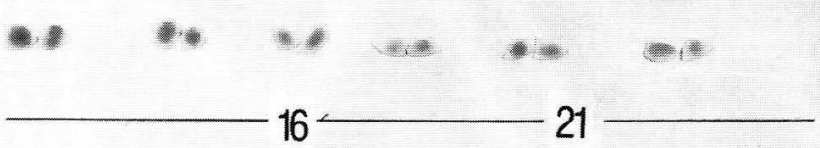

FIG. 2. Karyotypes of (A) Gonocephalus bellii, and (B) G. grandis. Bars equal $5 \mu \mathrm{m}$. 


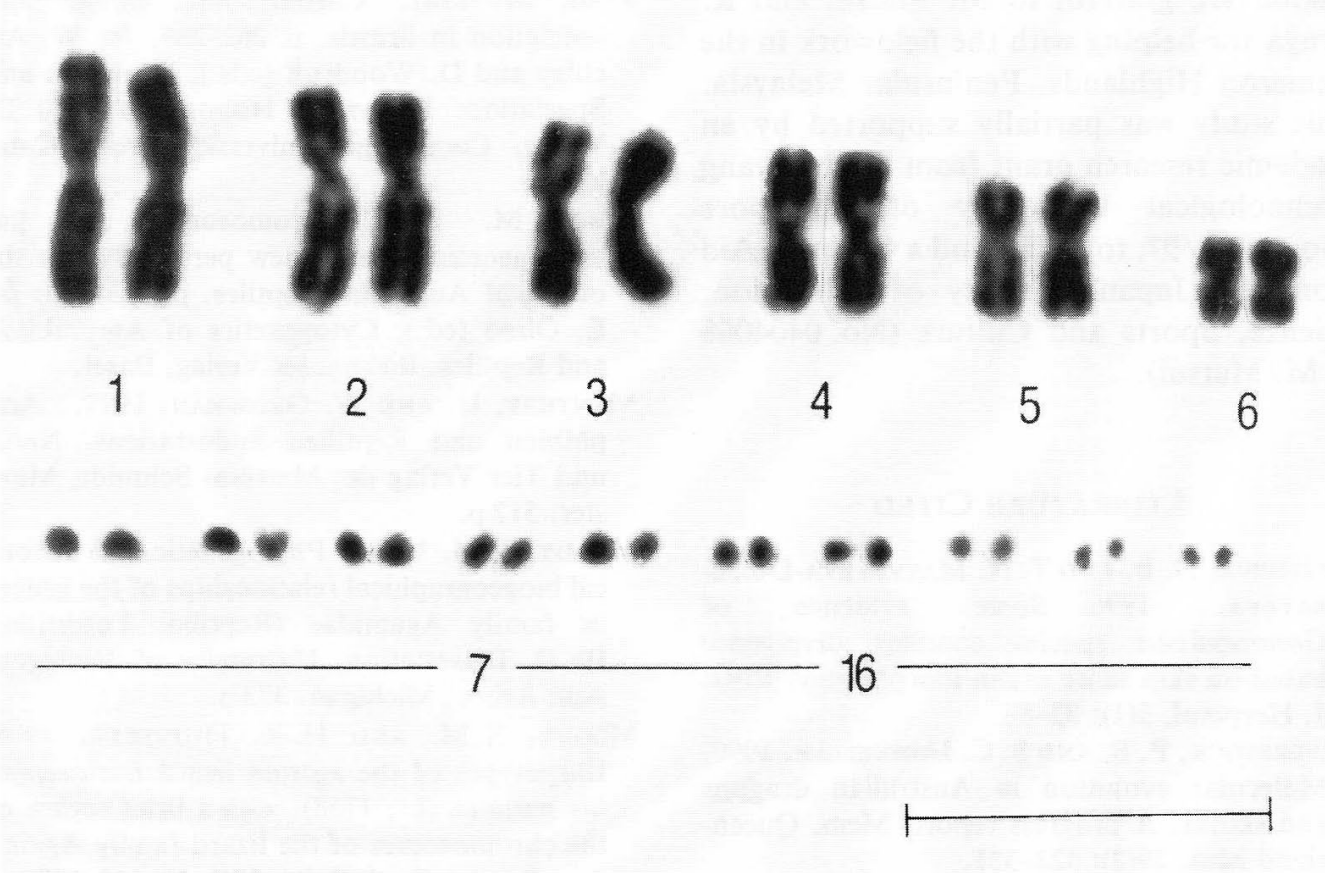

Fig. 3. Karyotype of Gonocephalus robinsonii. Bar equals $5 \mu \mathrm{m}$.

their monophyly, presumably along with some other species of the genus not yet studied karyologically.

The karyotype of $G$. robinsonii is similar to karyomorph (1), and considering remarkable differences in the diploid number of chromosomes or the arm number of macrochromosomes between this and other congeneric karyotypes (Table 2), it is unlikely that the karyotype of $G$. robinsonii directly arose from other congeneric karyotypes or vice versa. Thus, we conclude that the inclusion of this species in Gonocephalus would render the genus paraphyletic.

The number of microchromosomes (20) in the $G$. robinsonii karyotype is smaller than that in the typical agamid karyomorph (1)(22 or 24: Bickham, 1984; King, 1981). Such a chromosomal arrangement (i.e., $12 \mathrm{M}+20 \mathrm{~m}$ ) is exclusively shared with several agamid species that are supposedly derived from the Australian endemic radiation (Witten, 1983). It is thus probable that
G. robinsonii actually represents dispersals from the Australian Region into Southeast Asia like Physignathus cocincinus (see Honda et al., 2000). However, it is also probable that the karyotype of $G$. robinsonii is derived from karyomorph (1), exhibited by a number of other agamid species including several from Southeast Asia (see Ota and Hikida [1989]), through deletions of one or two microchromosome pairs. More comprehensive analyses using biochemical and molecular approaches are needed to determine the relationship of this enigmatic species with certainty.

\section{ACKNOWLEDGMENTS}

We thank the Institute of Biological Sciences, University of Malaya, Kuala Lumpur, for provision of facilities for experiments. We are also much indebted to J. A. Schulze for commenting on an early version of the manuscript. H. Ota and T. 
Hikida are grateful to M. Matsui and K. Araya for helping with the fieldwork in the Cameron Highlands, Peninsular Malaysia. This study was partially supported by an academic research grant from the Nanyang Technological University of Singapore (No. RP21/97, to CHD) and a Grant-in-Aid from the Japan Ministry of Education, Science, Sports and Culture (No. 0404068 to M. Matsui).

\section{Literature Cited}

Ananjeva, N. B. and T. N. Matveyeva-DujseBAYEVA. 1996. Some evidence of Gonocephalus species complex divergence based on skin sense organ morphology. Russ. J. Herpetol. 3(1): 82-88.

Baverstock, P. B. and S. C. Donnellan. 1990. Molecular evolution in Australian dragons and skinks: A progress report. Mem. Queensland Mus. 29(2): 323-331.

BickhaM, J. W. 1984. Patterns and modes of chromosomal evolution in reptiles. p. 13-40. In: A. K. Sharma and A. Sharma (eds.), Chromosomes in Evolution of Eukaryotic Groups, Vol. 2. CRC Press, Boca Raton, Florida.

Boulenger, G. A. 1885. Catalogue of the Lizards in the British Museum (Natural History). Vol. 1. Geckonidae, Eublepharidae, Uroplatidae, Pygopodidae, Agamidae. British Museum (Natural History), London. 497 p.

Darlington, P. J., JR. 1957. Zoogeography: The Geographical Distribution of Animals. John Wiley \& Sons, Inc., New York. 675 p.

Gorman, G. C. AND D. Shochat. 1972. A taxonomic interpretation of chromosomal and electrophoretic data on the agamid lizards of Israel with notes on some East African species. Herpetologica 28(2): 106-112.

GreEN, D. M. AND S. K. Sessions. 1991. Nomenclature for chromosomes. p. 431-432. In: D. M. Green and S. K. Sessions (eds.), Amphibian Cytogenetics and Evolution. Academic Press, San Diego, California.

Honda, M., H. Оta, M. Kobayashi, J. Nabhitabhata, H.-S. Yong, S. SengoKU, and T. HiKIDA. 2000. Phylogenetic relationships of the family Agamidae (Reptilia: Iguania) inferred from mitochondrial DNA sequences. Zoological Science 17(4): 527-537.
KING, M. 1981. Chromosomal change and speciation in lizards. p. 262-285. In: W. Atchley and D. Woodruff (eds.), Evolution and Speciation: Essays in Honour of M. J. D. White. Cambridge University Press, Cambridge.

KING, M. 1990. Chromosomal and immunogenetic data: A new perspective on the origin of Australia's reptiles. p. 153-180. In: E. Olmo (ed.), Cytogenetics of Amphibians and Reptiles. Birkhauser Verlag, Basel.

Manthey, U. and W. Grossman. 1997. Amphibien und Reptilien Sudostasiens. Natur und Tier Verlag des Matthias Schmidt, Munster. $512 \mathrm{p}$.

Moody, S. M. 1980. Phylogenetic and historical biogeographical relationships of the genera in family Agamidae (Reptilia: Lacertilia). Ph.D. Dissertation, University of Michigan, Ann Arbor, Michigan. 373 p.

Moody, S. M. AND H. R. Hutterer. 1978. Karyotypes of the agamid lizard Lyriocephalus scutatus (L., 1758), with a brief review of the chromosomes of the lizard family Agamidae. Bonner Zool. Beitr. 29(1-3): 165-170.

Olmo, E. 1986. Reptilia. p. 1-100. In: B. John (ed.), Animal Cytogenetics. Vol. 4. Chordata 3. Gebruder Borntraeger, Berlin and Stuttgart.

ОтА, H. 1988. Karyotypic differentiation in an agamid lizard, Japalura swinhonis swinhonis. Experientia(1) 44: 66-68.

ОтА, H. 1989a. Karyotypes of five species of Gekko (Gekkonidae: Lacertilia) from East and Southeast Asia. Herpetologica 45(4): 438443.

OтА, H. 1989b. A new species of Japalura (Agamidae: Lacertilia: Reptilia) from Taiwan. Copeia 1989(3): 569-576.

OTA, H. AND T. HiKidA. 1989. Karyotypes of three species of the genus Draco (Agamidae: Lacertilia) from Sabah, Malaysia. Jpn. J. Herpetol. 13(1): 1-6.

Ota, H., M. Matsui, T. Hikida, and A. Mori. 1992. Extreme karyotypic divergence between species of the genus Gonocephalus (Reptilia: Squamata: Agamidae) from Borneo and Australia. Herpetologica 48(1): 120-124.

Peccinini-Seale, D. 1981. New developments in vertebrate cytotaxonomy. IV. Cytogenetic studies in reptiles. Genetica 56(2): 123-148.

SOlleder, E. AND M. SCHMID. 1988. Cytogenetic studies on Sauria (Reptilia). I. Mitotic chromosomes of the Agamidae. Amphibia-Reptilia 9(3): 301-310. 
Urban, H. 1999. Eine neue Agamenart der Gattung Gonocephalus aus Papua-Neu Guinea (Squamata: Sauria: Agamidae). Herpetozoa 11(3/4): 185-188.

Welch, K. R. G., P.S. CoOKe, AND A. S. WRIGHT. 1990. Lizards of the Orient: A Checklist. Krieger Publishing Co., Malabar,
Florida. $162 \mathrm{p}$.

Witten, G. J. 1983. Some karyotypes of Australian agamids (Reptilia: Lacertilia). Aust. J. Zool. 31(4): 533-540.

Accepted: 2 August 2000 